Bell, SL., Phoenix, C., Lovell, R. and Wheeler, BW. (in press) Using GPS and geonarratives: a methodological approach for understanding and situating everyday green space encounters. Area [doi: tbc]

Abstract:

This methods paper contributes to the recent proliferation of methodological innovation aimed at nurturing research encounters and exchanges that facilitate indepth insights into people's everyday practices and routine place encounters. By drawing on the experiences of an interpretive study seeking to situate people's green space wellbeing practices within their daily lives, we suggest value in using personalised maps - produced using participant accelerometer (physical activity) and Global Positioning System (GPS) data - alongside in-depth and mobile 'go-along' qualitative interview approaches. After introducing the study and the methods adopted, the paper discusses three opportunities offered by this mixed method approach to contribute a more nuanced, contextualised understanding of participants' green space experiences. These include: (a) the benefits of engaging participants in the interpretation of their own practices; (b) the value of using maps to provide a visual aid to discussion about the importance of participants' routine, often pre-reflective practices; and (c) the production of a layered appreciation of participants' local green and blue space wellbeing experiences. Used in combination, such methods have the potential to provide a more comprehensive picture of how current green space experiences, be they infrequent and meaningful, or more routine and habitual, are shaped by everyday individual agency, life circumstances and past place experiences.

Key words: South West England; green space; wellbeing; GPS; geo-narratives; go-along interviews. 


\section{Using GPS and geo-narratives: a methodological approach for understanding and situating everyday green space encounters}

\section{Introduction}

Over the last decade, growing calls have been made for methodological innovation to enhance our understanding and interpretation of everyday practices and routines (Latham, 2003; Hitchings 2012). Whilst many of these practices may seem unremarkable or mundane, such as the daily commute to work, they could have important implications through repetition over time, both for our own wellbeing and that of the environment.

The challenge of exploring everyday actions, however, lies in their habitual, often prereflective nature, rendering them less 'tellable' than the more 'rehearsed' stories commonly volunteered within traditional interview circumstances (Holton and Riley, 2014). Researchers are increasingly taking up this challenge, drawing on a plurality of emerging research methods to nurture research encounters and exchanges that facilitate insights into participants' everyday lives (Ross et al., 2009). Methods have included, for example: PhotoVoice and photo elicitation interviews (Plane and Klodawsky, 2013); participant diaries and diary interviews (Latham, 2003); participatory video (Simpson, 2011); visual narrative inquiry (Riessman, 2008); visual and/or sensory ethnographies (Pink, 2009); and mobile methods such as 'go-along' interviews (Kusenbach, 2003). In addition, a number of map-based methods, including qualitative and participatory (or 'soft') Geographical Information System (GIS) approaches, have emerged that offer insights into the diverse and subjective ways in which people relate to and value their everyday living environments (Kwan and Ding, 2008; Hein et al., 2008; Kyttä et al., 2013). However, despite these many and varied methods, the potential for personalised GPS maps to offer springboards for discussion about routine spatial practices, the topic of this paper, has gained limited research attention to-date.

This methodological paper presents an innovative approach for examining everyday place encounters (mobile and sedentary), highlighting how maps depicting participants' own routine movements, activities and place interactions can act as a powerful tool for eliciting their stories. More specifically, it illustrates the potential to use personalised maps - produced using participant accelerometer (physical activity) and Global Positioning System (GPS) data - alongside in-depth and 'go-along' interview approaches in order to situate people's green space wellbeing practices within their everyday lives. Whilst the primary focus of the paper is on the methodological approach adopted, rather than the study findings, brief examples from the pilot and full study data are drawn upon to illustrate the value of integrating these methods.

\section{Methodological approach}

A significant body of evidence now exists regarding the wellbeing outcomes that may be promoted through green space exposure, including physical activity, social 
interaction, and restoration from stress or cognitive fatigue (Ulrich, 1983; Kaplan, 1995; Thompson-Coon et al., 2011; Hartig et al., 2014). However, many existing studies are underpinned by the potentially problematic assumption that if people have access to nearby green spaces, they will use them. In awareness of this issue, Hitchings (2013: 99) calls for green space studies to start with an understanding of our everyday lives ("the power of personal routine") in order to explore the complex personal factors that shape individual capacity and inclination (or 'agency') to pro-actively engage with different green spaces (for wellbeing or otherwise).

Focusing on residents of two urban communities in Cornwall, England, the study sought to understand how participants interacted with different types of green spaces for wellbeing, and to examine how these encounters were shaped by their daily routines, life circumstances and past place experiences. Each study area lay in close proximity to a diversity of green spaces, including: (a) 'planned' spaces such as landscaped parks, playgrounds, allotments and formal gardens; and (b) areas considered more 'natural' by participants, such as countryside, woodlands, beaches, rivers, and coastal paths (the latter three could also be characterised as 'blue' but are described as 'green space' in this paper for purposes of brevity).

An interpretive, three-stage mixed methodology was designed to meet the study aims. This combined data collected using personal GPS receivers and accelerometers with indepth map-based interviews, and a subset of case study go-along interviews. The approach was piloted with seven participants from January to March 2013, and the full study conducted with 33 participants from May to November 2013.

In order to gain insights into the value of green spaces for wellbeing across a diversity of everyday situations, a purposive sampling matrix was developed, capturing variation in gender, life circumstance and green space engagement. Participants were recruited following the delivery of information sheets and recruitment screening questionnaires to 3000 households within the study areas. The research was discussed further with all individuals who included contact details in their returned screening questionnaires (65 individuals), resulting in the recruitment of 26 participants. As relatively few males responded, snowballing was undertaken to recruit an additional seven males, increasing the sample to 33 participants (13 male). The final sample composition included participants with varying levels of green, blue and built space engagement, and captured varied life circumstances, including individuals: aged between 25-85 years old; in full/part-time employment or retired; with or without children; and spanning households earning less than $£ 20 \mathrm{k} /$ year up to $£ 70 \mathrm{k} / \mathrm{year}$.

At no point during the study was green space indicated by the study materials or the researcher to be the primary research focus. The study was framed in a way that asked participants how they interact with their 'local environment' for 'health and/or happiness', and the recruitment materials included a small black and white collage depicting diverse indoor, built, green and blue space images. In this way, it sought to reduce the risk of recruiting only those individuals who self-identify with green space. 
This framing may still, however, have discouraged responses amongst those who primarily engage in indoor, home-based activities (e.g. screen-based pursuits). Ethical approval for the study was granted by the university Research Ethics Committee (Approval Reference: Jan13/B/001).

\subsection{Stage one: combining GPS with accelerometry}

Studies interested in linking physical activity levels to place have highlighted the value of using accelerometers to provide an objective measure of physical activity levels (Haskell, 2012). In this study, accelerometers were worn by participants on their wrist for seven days, logging their activity levels at 10 second (s) intervals. To record location at similar intervals, participants were also asked to carry a small GPS unit. The integrated location/activity data were then mapped with a Geographical Information System (Quantum GIS v.1.8, www.qgis.org) (Wheeler, 2010).

The study was designed to harness the potential of the GPS/accelerometer data to provide a visual representation of participants' routine place interactions, specifically depicting location and relative levels of physical activity. Between 20 and 40 maps were made for each participant, including: an overall activity plot depicting seven days' worth of data; individual week-day plots; and higher resolution plots focusing on separate journeys or activity clusters occurring each day. These maps were used to guide discussion in subsequent interviews with participants in Stage 2, allowing an indepth interpretive exploration of the ways in which participants were consciously or subconsciously interacting with their local environments for different dimensions of wellbeing, broadening the focus beyond physical activity.

\subsection{Stage two: in-depth map-based interviews}

Interviews are "an ideal method for exploring people's biographies and perceptions of self, others, and place... people tell what they do and why they do it" (Carpiano, 2009: 266). Using active listening to build trust, rapport and shared understanding, in-depth interviews encourage participants to reveal 'private' perspectives, rather than the 'public' accounts often volunteered in standardised survey approaches where rapport is minimal (Grinyer and Thomas, 2012).

The first half of each interview focused on the maps, asking participants to describe the movements and activities depicted in their own terms. Open probes were used to explore participants' place stories further, considering: (a) frequency of, and motivations for, the interactions; (b) associated emotions and/or meanings; (c) physical context; (d) social context; and (e) changes over time. Although it was suggested that participants could focus primarily on place interactions linked to their perceived 'health or happiness' (positively or negatively), in practice they were keen to make sense of all their movements and clusters. Whilst this added to the duration of each interview, many of the resulting narratives proved useful in contextualising wellbeing experiences in participants' everyday routines. 
In the second half of each interview, similar probes were used to encourage participants to describe salient wellbeing-related places and activities not depicted in the maps. This highlighted the extent to which green spaces featured amongst participants' more 'meaningful' everyday places. At this point, questions were also asked about: places avoided by participants; spaces they felt were missing locally; and how 'typical' they felt the maps were of their usual routines. Throughout these discussions, participants tended to refer to the maps as a recall aid.

\subsection{Stage three: the case study 'go-along' interviews}

Traditional interviews have been criticised for being unable to understand 'lived experiences' of place, as interviewees may struggle to articulate visually elusive or prereflective aspects of experience (Carpiano, 2009). In contrast, 'emplaced interviews' those conducted within the place under study - allow the researcher "to witness an array of embodied and emotional practices as they are experienced and performed by those involved" (Anderson and Jones, 2009: 299). During emplaced 'go-along' interviews, research participants literally walk the researcher through their place experiences, and by asking questions and observing, the researcher can examine the informant's practices and interpretations within a place of interest (Carpiano, 2009).

The insights gained into participants' everyday experiences in Stages 1 and 2 were complemented in Stage 3 by a subset of case study go-along interviews, in which participants were accompanied by the researcher (SB) on a visit to a local place highlighted in their previous interview as important for their wellbeing. Locations included beaches, ponds, parks, trails, gardens, harbours, and indoor leisure spaces. These interviews offered a nuanced understanding of the relational dynamics of participants' place encounters, including relations to other people and elements of the places themselves.

Each go-along interview lasted between one and five hours (based on participant preference). Interviewees were selected purposively to reflect a variety of life stages. A relatively informal approach was adopted, where the researcher joined participants in their chosen location as they would normally go (be it alone or with a partner, children, dog). Participants were asked to guide the visit and discussion, highlighting any aspects of the place of importance to them (Kusenbach, 2003). Open thematic probes were used as appropriate, focusing on feelings experienced in the place, early or favourite memories of visiting, personal place meanings, and changes over time. These were coupled with observations, including: where stories were volunteered and why; changes in participants' posture, pace, mood and tone in response to the surroundings; how different sensory stimuli captured participants' attention; participant responses to people and/or wildlife present in the environment; and the route taken through the space.

\subsection{Analytical approach}


Multiple phases of analysis were undertaken on the data collected. As noted above, the Stage 1 data were used to produce personalised maps which were co-analysed with participants in Stage 2. Full immersion in the Stage 2 and 3 interview transcripts and accounts then informed the development of an initial coding framework, depicting broad and nested wellbeing place and experience themes emerging from the data. This framework, together with participants' transcripts, were uploaded to Nvivo 10 (qualitative analysis software), where additional codes began to emerge as the indepth qualitative data analysis phase progressed. Drawing on elements of Pamphilon's (1999) 'zoom' model, this phase considered how the diverse wellbeing green space experiences recounted by participants reflected: (a) existing cultural place narratives (the macro-zoom); (b) specific personal identities, relationships, priorities, preferences and emotions (meso and micro-zooms); (c) shifts over time, specifically regarding the influence of different life transitions (meso-zoom); and (d) the interview context itself (the interactional-zoom). The final phase of analysis focused on the analytical generalisability of the findings, considering similarities and variations in the wellbeing experiences emerging across participants' accounts in relation to different green space interactions, life circumstances and transitions, and personal identities.

\section{The value of combining GPS/accelerometers, in-depth and mobile interviewing approaches}

Taken in isolation, each of the three methods used in this study offer significant research strengths and challenges, as touched on above. In this section we highlight three particularly valuable opportunities offered by this combined approach for providing a contextualised, in-depth understanding of participants' diverse green space experiences.

\subsection{Engaging participants in the interpretation of their own practices}

The first opportunity concerns the value of engaging participants in the analysis and interpretation of the activities depicted on their GPS/accelerometer maps. The stories offered by participants in relation to the observed place interactions were coconstructed with the researcher, which afforded subjective insights that are often overlooked by studies reliant solely on researcher-led analysis and interpretation. Such insights included: (a) perceived drivers of the depicted movements and place interactions and recalled changes over time; (b) participant perceptions of their local environments; and (c) the diverse ways in which participants engaged with local places for personally salient wellbeing dimensions. For example, the GPS plots and associated interview extracts presented in Figure 1 offer a snapshot of how the green and blue spaces within one small area were perceived and experienced differently by five participants. The interview extracts allude to varied physical activity benefits (walking, cycling, golf) as well as opportunities for a sense of perspective, achievement, time out and purposive family leisure.

Several participants appreciated the opportunity to discuss their maps and to contribute to how their activities would be represented by the study. Some felt 
disappointed, for example, that they were unable to visit certain places whilst wearing the devices but were keen for these places to be acknowledged as important to them. Others were anxious that their activity levels would be under-reported, particularly if they had been limited by illness, poor weather conditions or work demands. As noted by one participant in her seventies, for example: "If it had been a lovely week of weather I would've walked far more along the [sea] front... through the woods, by the stream, it's beautiful in there... When the rain stopped, I got thoroughly muddy just because I wanted to show you that I did walk!" Another participant guiltily admitted, during the co-interpretation of her data, to giving her husband the equipment to wear on the Saturday as she was unexpectedly called into work over the weekend, which she felt would not have given a fair representation of their usual weekend activities.

An advantage of this methodology lies in understanding how stories recounted in response to different place interactions reflect certain personality traits, personal identities, or wellbeing priorities, and how perspectives emerged and evolved through the interviews (Sparkes, 2005). For example, one participant initially spoke fondly of the local park as a great place to spend time with her children and to meet other parents. However, later in the interview, speaking as someone with a strong sense of attachment to the sea, she described the park as a 'compromise' in that it allows quality time with the children but does not meet her need for the sense of openness and perspective she experiences at the coast. Understanding such shifts, and the desire to express different identities or priorities, is integral to this type of interpretive approach (Gubrium and Holstein, 2012), and helps to characterise participants beyond the commonly considered dimensions of gender, age, ethnicity and socio-economic status.

\subsection{A visual representation of routine movements and interactions}

A particular strength of this methodology over traditional interviewing was the role of the maps in providing a visual aid to discussions about the importance of participants' routine practices. By focusing on the clusters and movements depicted on the maps, it was possible to explore where and why participants lingered, diverted and changed pace in their local environment. Such temporal insights have typically been noted as an advantage of go-along interview methods (Evans and Jones, 2011; Riley, 2010) but also emerged as an unexpected benefit of these personalised map-based interviews. This may be of value for those looking to understand these dimensions of routine place interaction without the potential intrusion of the researcher's physical presence, which can be an issue during go-along interviews (Kusenbach, 2003).

A clustering of GPS dots in one location suggested participants had chosen to 'linger' there rather than moving directly through. Whilst this sometimes corresponded with a significant place connection (be it functional or emotional), this was not always the case. For example, one participant appeared to spend much of his Sunday afternoon in some formal gardens near to his home. When asked how often he visits, he explained that he was only there for the prize giving of a race he'd been marshalling that day. 
Moreover, he indicated a general lack of interest in such formal, landscaped green spaces, preferring to relax, socialise and be active in more natural countryside, wooded, or coastal areas. Without discussing his maps with him, the lingering conveyed by the maps could have been misinterpreted as a preference for these formal garden-type green spaces.

Several participants highlighted the importance of routine but fleeting green space encounters upon seeing their maps. For example, some took deliberate detours between places to include moments of calm in otherwise busy lives or to see specific views which seemed to contribute to their sense of place. The latter is illustrated in Figure 2, in which Tara explains why she regularly detours to see a certain view over the south coast when driving home from her allotment. Whilst only encountered momentarily from the car window, she feels that view captures the character of Cornwall. The same view was mentioned by another participant, Zoe, who sometimes diverts there en route home from work to remind herself that she made the right decision to move to Cornwall. A similar sentiment was expressed by Helen, who explained the personal salience to her of Carlyon Bay upon seeing her maps. As indicated in Figure 3, this is not her favourite place aesthetically, but she appreciates the opportunities it provides to see the sea en route to work and to incorporate the coastal path (albeit briefly) within her regular running route. Interestingly, Helen refers to a point during her run where she likes to pause briefly and watch the movement of the sea; this point is marked in Figure 3, illustrated by the accumulation of lower activity GPS points.

\subsection{Generating in-depth detail about everyday experiences}

A layered appreciation of participants' local place experiences was gained through the combination of methods used. This includes a layered understanding of the different wellbeing dimensions of participants' green space experiences (e.g. social, active/passive, achieving, symbolic, immersive), as well as temporal layering, considering how current place preferences have been shaped by past experiences. With regards to the former, the go-along interviews were particularly valuable in providing subtle insights into the social contexts of participants' wellbeing encounters. For example, in Amy's map-based interview she expressed strong feelings against the presence of other people during her long walks within a nearby, semi-natural ancient woodland. In being exposed to passing conversations, she felt she was pulled back into the 'real world' and its associated stresses. However, in her subsequent go-along interview along that route she initiated and engaged happily in three different sets of conversations with other dog walkers. When probed, she responded: 
Amy: "It's not like there's people all the time and I can hear the conversations that they're having about work and all this stuff. That's what I don't like, when it's reminding me about real life. But when it's just like "oooh it's lovely weather" and silly conversations like that, it's fine, 'cos then you can pop back into your little brain again"

This example also reflects a widely recognised benefit of mixed method approaches; that of 'complementarity', whereby understandings gained from one method are clarified and developed through the use of another (Moran et al., 2011).

With regards to temporal layering, several participants attributed their current wellbeing place preferences to the cumulative influence of past place experiences, with some explicitly commenting on the importance of childhood encounters. Sally, for example, spent much of her interview highlighting the importance to her of sea views, and the sense of openness, perspective and peace she feels when walking along the coastal path. This is something she both craves and relishes after having lived in Central London for over 30 years. Towards the end of the interview, however, she was describing her swimming routine at the local leisure centre and, when asked whether she ever goes sea swimming, she responded:

Sally: "No! I can't see underneath. No, it's that Jaws film ((laughs)). When I was little, that did it for me! Even when I went to Greece on my own many many years ago and the water was crystal clear and, you know, you walk out to about your knee depth and then you start seeing the little fishes and I had to get out. I can't, 'cos it's like, well if they can get in there, a shark can come in! It's psychological, I know it's stupid, but no I can't... I'm not a sea person activity-wise"

Sally's reaction to sea swimming highlights an important distinction in how she enjoys engaging with the sea; as a landscape to look over whilst walking, rather than a waterbased activity space in which to be immersed. She highlights how the thought of actually swimming in the sea rekindles her childhood fear of sharks, linked to the 1975 thriller film, Jaws. Importantly, this line of discussion would not have occurred if the leisure centre interaction had not been depicted in her maps. An appreciation of these life-course influences, including the role of past place experiences (physical and virtual), is still largely lacking in the epidemiological and experimental green space and health evidence base, though has been touched on by other small-scale qualitative studies (for example, Milligan and Bingley, 2007; Skår, 2010).

\section{Conclusions}

This paper has explored how GPS and accelerometer data can usefully be combined with in-depth and mobile interviewing techniques within interpretive, exploratory place-based research. In doing so, it responds to calls for methodological innovation to 
enhance our understanding and interpretation of everyday practices and routines (Latham, 2003; Anderson and Jones, 2009).

Before summarising the benefits of the combined approach, two limitations should be highlighted. Firstly, the technology is not foolproof, and relies on participant cooperation and patience. Although the equipment used in this study was less than two years old, three accelerometers and one GPS unit broke, resulting in data loss and participant disappointment. Secondly, the three stages constitute a significant time commitment, both from the researcher and participants (which may have constrained recruitment to the study and hindered opportunities to undertake go-along interviews with some of the more time-limited participants). Since many participants were keen to undertake the in-depth interview soon after wearing the devices for recall purposes, several of the Stage 1 and 2 tasks were conducted in parallel, including: preparing, delivering and collecting multiple devices; processing the data and producing participants' maps; tailoring interview guides; and conducting in-depth interviews (all whilst still actively trying to recruit additional participants). Future studies would therefore benefit from having more than one researcher in the field, particularly within multi-site studies or with larger sample sizes. Nonetheless, the three opportunities discussed in this paper - engaging participants in the analysis of their own practices, offering a visual representation of routine movements, and generating in-depth detail on everyday experiences - suggest value in this effort.

Engaging participants in the interpretation of their own GPS/accelerometer activity maps encouraged detailed accounts of participant's green space experiences in their own terms, offering subjective insights into participants' shifting wellbeing needs and priorities and the ways in which they sought to meet them through diverse local place interactions. The personalised maps, in particular, provided a visual representation of participants' everyday movements, and encouraged the sharing of stories linked to these movements. Valuable temporal insights were gained in this way, exploring the varying personal importance of routine places in which they paused, settled or deliberately diverted towards, even if fleetingly. For example, the limited data presented in this paper highlighted the contribution to participants' sense of place and belonging of taking brief detours to appreciate specific viewpoints, often those incorporating the coast and countryside.

Layered understandings of participants' wellbeing encounters were also gained through the combined approach. This included an appreciation of the multiple wellbeing dimensions (or 'layers') contributing to participants' green space experiences and of the cumulative influence of past place experiences on current green space interactions and preferences (as illustrated by Sally's appreciation for the spaciousness encountered at the coast after feeling enclosed in London for many years, but her reluctance to swim in the sea due to childhood fears of sharks).

Future studies could build on this approach, perhaps incorporating time-lining (Sheridan et al., 2011) or themed life histories (Uzzell et al., 2010) to facilitate an in- 
depth interpretive examination of shifts in place interactions over time. Used in combination, these methods could offer a comprehensive picture of how current place experiences (be they infrequent and meaningful or more pre-reflective and habitual) are shaped by our everyday individual agency, life circumstances and socio-cultural context, and our past place experiences.

\section{References}

Anderson J and Jones K. (2009) The difference that place makes to methodology: uncovering the 'lived space' of young people's spatial practices. Children's Geographies 7: 291-303.

Carpiano R. (2009) Come take a walk with me: the 'Go-Along' interview as a novel method for studying the implications of place for health and wellbeing. Health and Place 15: 263-272.

Evans J and Jones P. (2011) The walking interview: Methodology, mobility and place. Applied Geography 31: 849-858.

Grinyer A and Thomas C. (2012) The value of interviewing on multiple occasions or longitudinally. In: Gubrium J, Holstein J, Marvasti A, et al. (eds) The SAGE Handbook of Interview Research: The Complexity of the Craft. Second ed. California, US: SAGE Publications, 219-230.

Gubrium J and Holstein J. (2012) Narrative practice and the transformation of interview subjectivity. In: Gubrium J, Holstein J, Marvasti A, et al. (eds) The SAGE Handbook of Interview Research: The Complexity of the Craft. Second ed. California, US: SAGE Publications, 27-44.

Hartig T, Mitchell R, de Vries S, et al. (2014) Nature and Health. Annual Review of Public Health 35: 207-228.

Haskell W. (2012) Physical activity by self-report: a brief history and future issues. Journal of Physical Activity and Health 9: S5-S10.

Hein J, Evans J and Jones P. (2008) Mobile Methodologies: Theory, technology and practice. Geography Compass 2: 1266-1285.

Hitchings R. (2012) People can talk about their practices. Area 44: 61-67.

Hitchings R. (2013) Studying the preoccupations that prevent people from going into green space. Landscape and Urban Planning 118: 98-102.

Holton M and Riley M. (2014) Talking on the move: place-based interviewing with undergraduate students. Area 46: 59-65.

Kaplan S. (1995) The restorative benefits of nature: Toward an integrative framework. Journal of Environmental Psychology 15: 169-182.

Kusenbach M. (2003) Street Phenomenology: the Go-Along as ethnographic research tool. Ethnography 4: 455-489. 
Kwan M and Ding G. (2008) Geo-narrative: Extending Geographic Information Systems for Narrative Analysis in Qualitative and Mixed-Method Research. The Professional Geographer 60: 443-465.

Kyttä M, Broberg A, Tzoulas T, et al. (2013) Towards contextually sensitive urban densification: location-based softGIS knowledge revealing perceived residential environmental quality. Landscape and Urban Planning 113: 30-46.

Latham A. (2003) Research, performance, and doing human geography: some reflections on the diary-photograph, diary-interview method. Environment and Planning A 35: 1993-2017.

Milligan C and Bingley B. (2007) Restorative places or scary spaces? The impact of woodland on the mental wellbeing of young adults. Health and Place 13: 799811.

Moran A, Matthews J and Kirby K. (2011) Whatever happened to the third paradigm? Exploring mixed methods research designs in sport and exercise psychology. Qualitative Research in Sport, Exercise and Health 3: 362-369.

Pamphilon B. (1999) The Zoom Model: A dynamic framework for the analysis of life histories. Qualitative inquiry 5: 393-410.

Pink S. (2009) Doing Sensory Ethnography, London: SAGE Publications.

Plane J and Klodawsky F. (2013) Neighbourhood amenities and health: examining the significance of a local park. Social Science and Medicine 99: 1-8.

Riessman, CK. (2008) Narrative Methods for the Human Sciences, London: SAGE Publications.

Riley M. (2010) Emplacing the Research Encounter: Exploring Farm Life Histories. Qualitative inquiry 16: 651-662.

Ross N, Renold E, Holland S, et al. (2009) Moving stories: using mobile methods to explore the everyday lives of young people in public care. Qualitative Research 9: 605-623.

Sheridan J, Chamberlain K and Dupuis A. (2011) Timelining: visualizing experience. Qualitative Research 11: 552-569.

Simpson P. (2011) 'So, as you can see...': some reflections on the utility of video methodologies in the study of embodied practices. Area 43: 343-352.

Skår M. (2010) Forest dear and forest fear: dwellers' relationships to their neighbourhood forest. Landscape and Urban Planning 98: 110-116.

Sparkes A. (2005) Narrative analysis: exploring the whats and hows of personal stories. In: Holloway I (ed) Qualitative research in health care. Maidenhead: Open University Press, 191-209.

Thompson-Coon J, Boddy K, Stein K, et al. (2011) Does participating in physical activity in outdoor natural environments have a greater effect on physical and mental wellbeing than physical activity indoors? A Systematic Review. Environmental Science and Technology 45: 1761-1772. 
Ulrich R. (1983) Aesthetic and affective response to natural environment. In: Altman I and Wohlwill J (eds) Human Behaviour and Enviroment: Advances in theory and research. New York: Plenum, 85-125.

Uzzell D, Gatersleben B and White E. (2010) Using the life histories approach to understand the development of outdoor preferences and practices: Report for the Outdoors and Health Network, ESRC Grant no. RES-355-25-0040.

Wheeler B, Cooper A, Page A, et al. (2010) Greenspace and children's physical activity: A GPS/GIS analysis of the PEACH project. Preventive Medicine 51(2): 148-52. 


\section{Figure 1. The diverse wellbeing experiences valued by different participants in one local area}

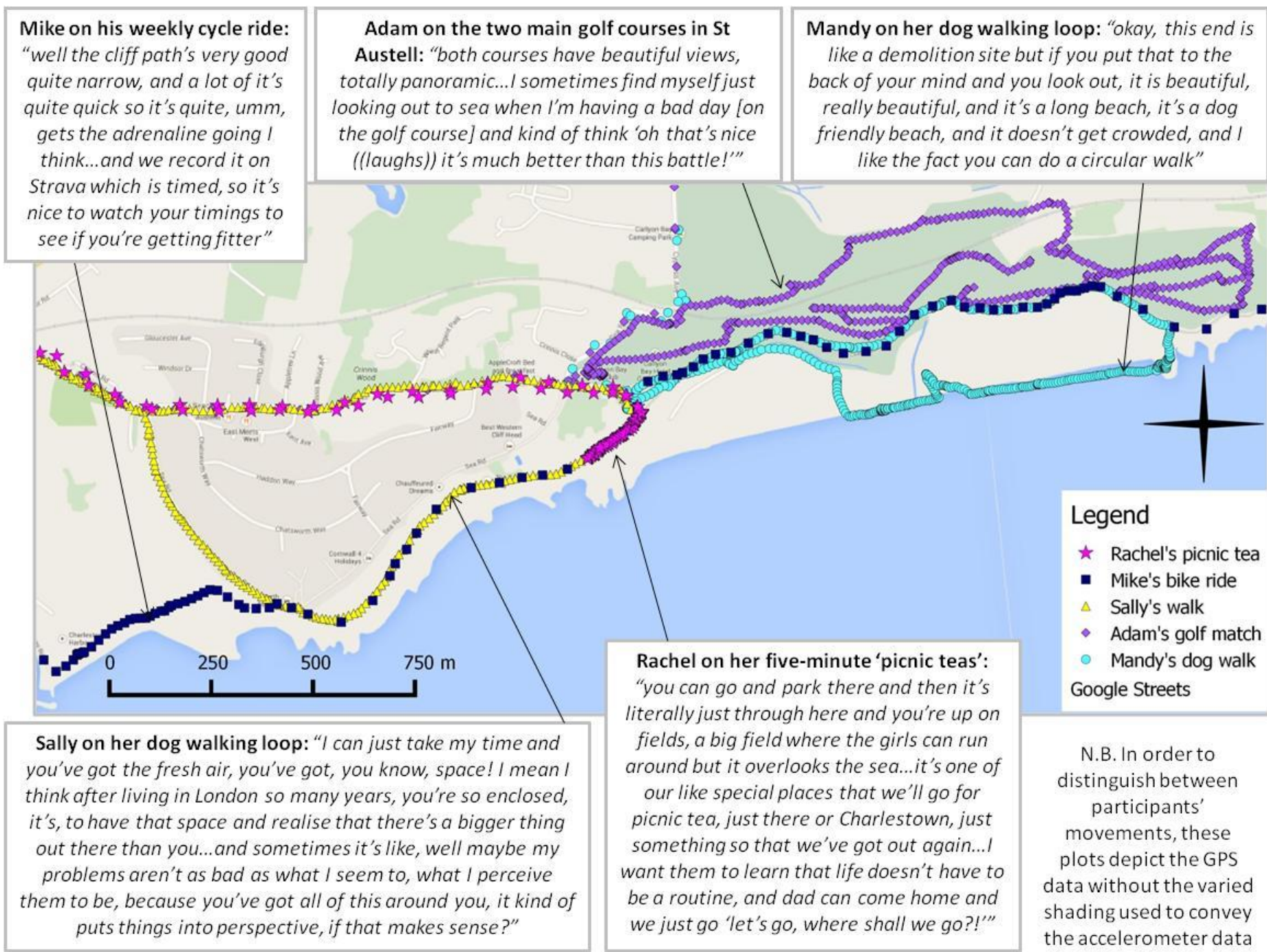




\section{Figure 2. The contribution of a fleeting detour to personal sense of place}

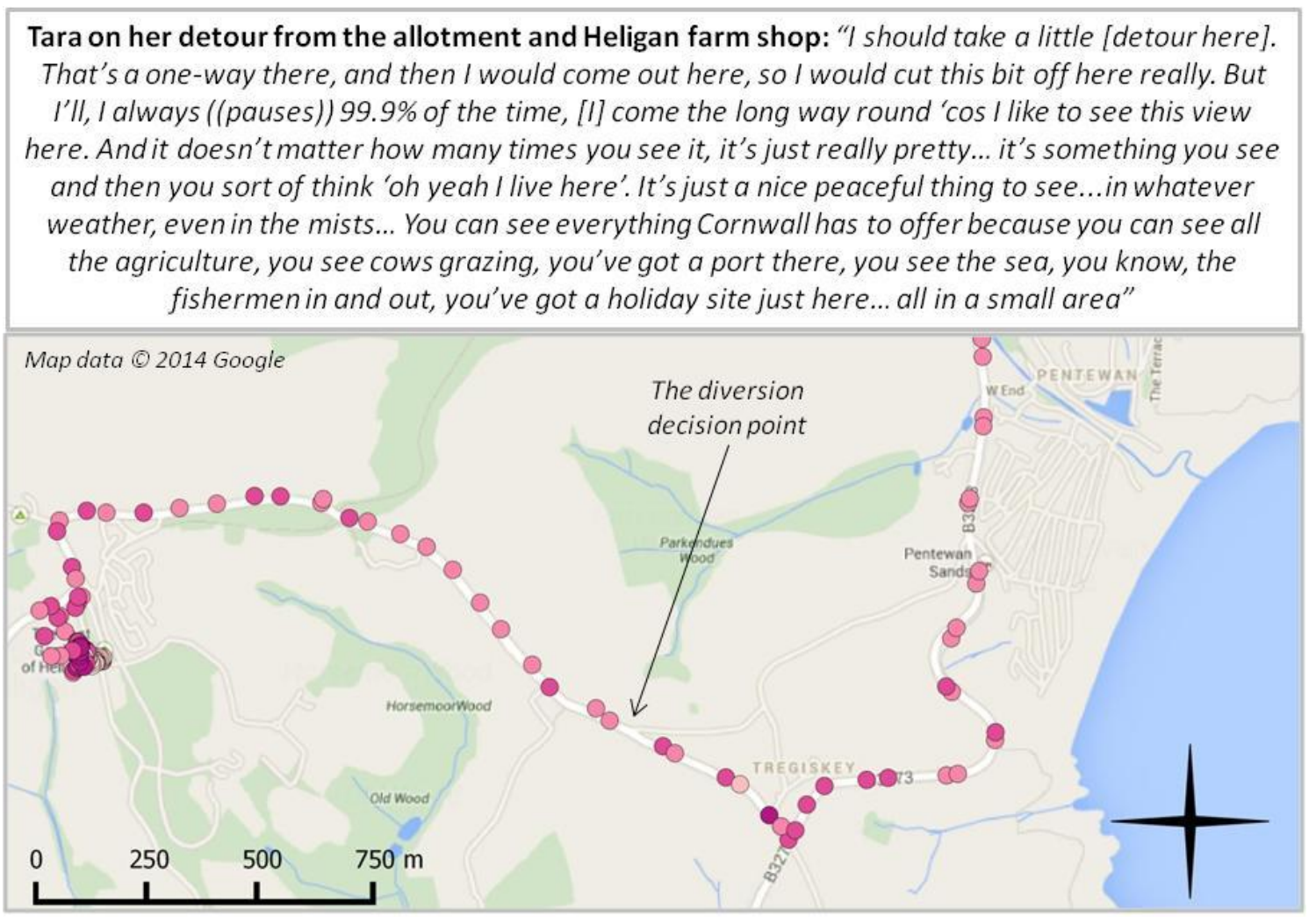

N.B. A dot is plotted every 10 seconds (provided the GPS could detect signal). The colour of the dot corresponds to the overall activity level detected by the accelerometer, whilst the location of the dot is determined by the associated GPS reading. Darker coloured dots indicate greater overall accelerations per 10 s time period (i.e. participants were being more active). The greater the distance between the dots, the faster the GPS unit was travelling. 


\section{Figure 3. Efforts to incorporate a valued green (blue) space type within the weekly routine}

\begin{tabular}{c||c|}
\hline $\begin{array}{c}\text { Helen on her weekly run route: "it doesn't actually look like that much of a } \\
\text { run now but it's sort of worth it 'cos you, when I get to, I don't even know } \\
\text { where it is, probably there, I can actually stand and look at the sea for a bit, } \\
\text { which is just very special, I love looking at the sea, so yeah, it's all to do with } \\
\text { seeing the sea and getting out to the countryside" }\end{array}$ & $\begin{array}{c}\text { Helen on being able to see the sea en route to } \\
\text { work: "When I discovered that I could walk to } \\
\text { work and I could walk back again, it was } \\
\text { unbelievably special to walk along the coastal } \\
\text { path and watch the sea... that was magical" }\end{array}$ \\
\hline
\end{tabular}

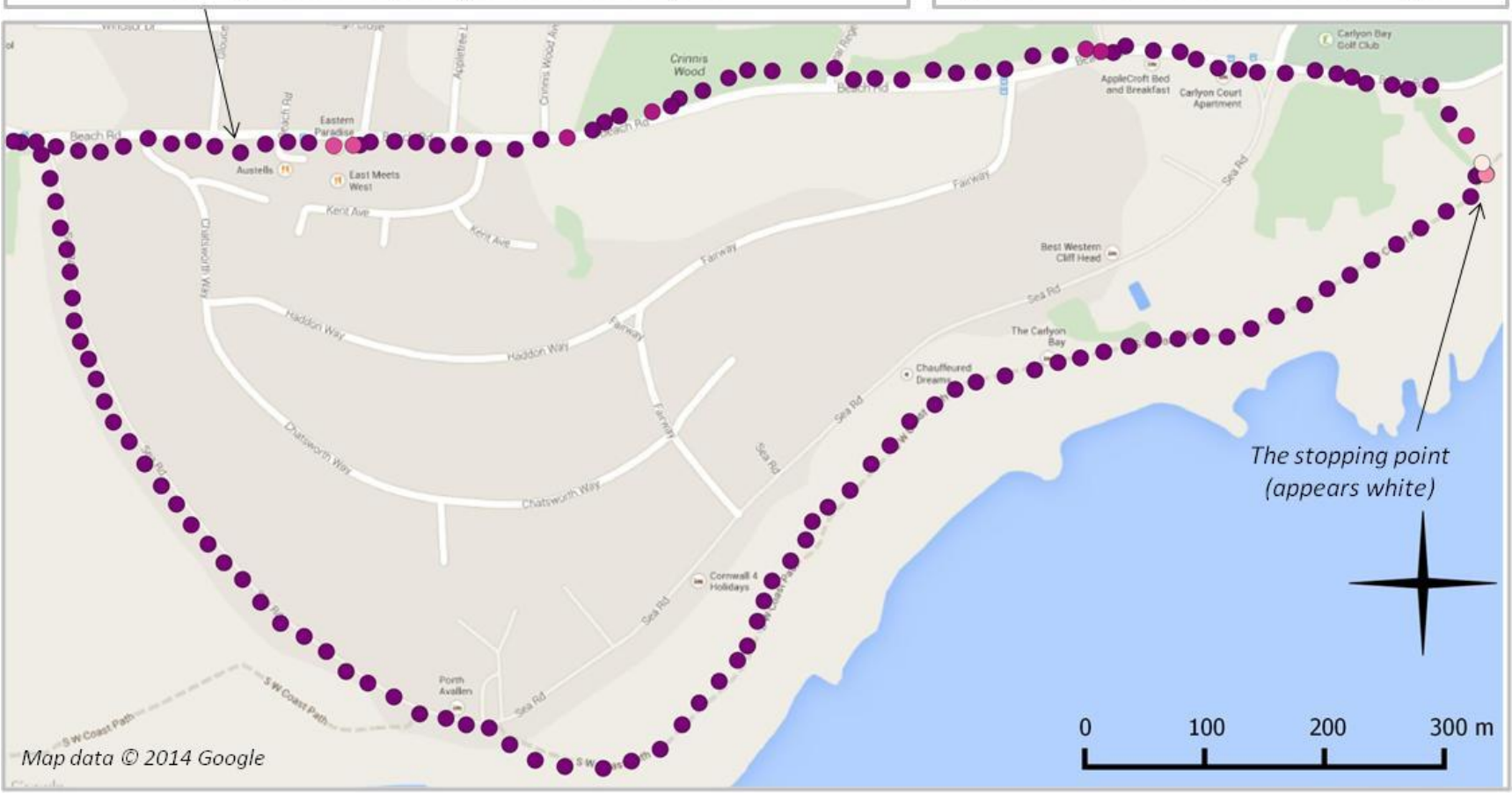

Helen on meaningful places locally: "when I came down ((to Cornwall)) for interview, I was early for the second morning and I wanted to look at the sea, and I just followed a sign - I thought Bay, Carlyon Bay, that has to be a sea - so I followed the signs and eventually got there and I was standing there looking at it thinking, 'no, I do want to be here, this is where I want to be'. So it's not the most beautiful place in the world but that view to me sort of is the future as in the possibility, so that's, that's very special" 